\title{
NEBULIZED SYNTHETIC SURFACTANT IN REPERFUSION INJURY AFTER SINGLE LUNG TRANSPLANTATION
}

\author{
Martin Strüber, MD, Joachim Cremer, MD, Wolfgang Harringer, MD, Stephan W. Hirt, MD,
} Angelika Costard-Jäckle, MD, and Axel Haverich, MD, Kiel, Germany

Reperfusion injury is one of the major causes of early morbidity and mortality after lung transplantation. Features of this syndrome are pulmonary edema, reduction of compliance, and impaired gas exchange, and these occur in about $20 \%$ of all lung transplant recipients. Usual treatment includes prolonged mechanical ventilation with elevated positive end-expiratory airway pressure (PEEP), enhanced mean airway pressure with high oxygen content $\left(\mathrm{FiO}_{2}\right)$, and, in severe cases, inverse ratio ventilation and extracorporeal membrane oxygenation. We report on the successful treatment with nebulized synthetic surfactant (Exosurf; Wellcome, Burgwedel, Germany) of a patient in whom reperfusion injury developed 5 hours after right lung transplantation.

Right lung transplantation was done in a 26-year-old woman who had sarcoidosis with terminal interstitial lung disease and recurrent failure of the right side of the heart. The patient had been dependent on continuous oxygen insufflation for 30 months before transplantation. Pulmonary hypertension was present with a mean pulmonary artery pressure of $50 \mathrm{~mm} \mathrm{Hg}$.

From the Department of Cardiovascular Surgery, ChristianAlbrechts University, Kiel, Germany.

J THORAC CARDIOVASC SURG 1995;110:563-4

Copyright (C) 1995 by Mosby-Year Book, Inc. $0022-5223 / 95 \$ 3.00+0 \quad \mathbf{1 2 / 8 / 5 8 9 5 1}$
The surgical procedure was complicated by severe pleural adhesions. Extracorporeal circulation was required to perform pneumonectomy of the right lung safely. In addition, an oversized donor lung prevented bilateral transplantation.

During the first 5 postoperative hours signs of reperfusion injury occurred: $\mathrm{FiO}_{2}$ had to be increased from $35 \%$ to $60 \%$ to prevent hypoxia, the compliance dropped to 15 $\mathrm{ml} / \mathrm{mm} \mathrm{Hg}$, and edema of the transplanted lung was found clinically and on chest x-ray film 6 hours after transplantation. At this time mean pulmonary artery pressure was increased ( $32 \mathrm{~mm} \mathrm{Hg}$ ), the use of catecholamines was not required, and prostacyclin infusion at a rate of $20 \mu \mathrm{g} / \mathrm{hour}$ had already been started on the patient's arrival at the intensive care unit. Placement of the patient in the prone position for 3 hours did not improve the clinical situation. At this point, surfactant replacement was started with nebulized synthetic surfactant at a rate of $3 \mathrm{gm}$ per hour with use of a commercially available nebulizer and mechanical ventilator (Evita 2; Dräger, Lübeck, Germany). The ventilator allows for measurement of dynamic compliance, mean airway pressure, and PEEP.

After 30 minutes of surfactant therapy a remarkable increase of the compliance from 16 to $30 \mathrm{ml} / \mathrm{mm} \mathrm{Hg}$ was found (Fig. 1). As a consequence, without a change in airway pressure, the tidal volume rose from $400 \mathrm{ml}$ to $700 \mathrm{ml}$. Surfactant therapy was continued for 24 hours. During the therapy with nebulized synthetic surfactant prostacyclin infusion was continued at the same rate. The

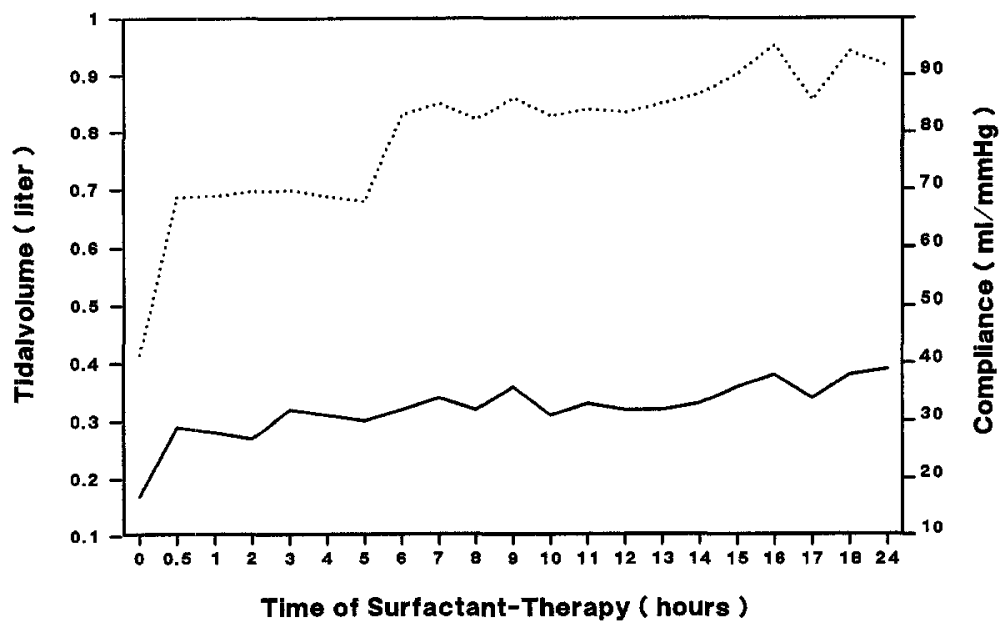

Tidalvolume

Compliance

Fig. 1. Increase of compliance and tidal volume during surfactant replacement therapy. 


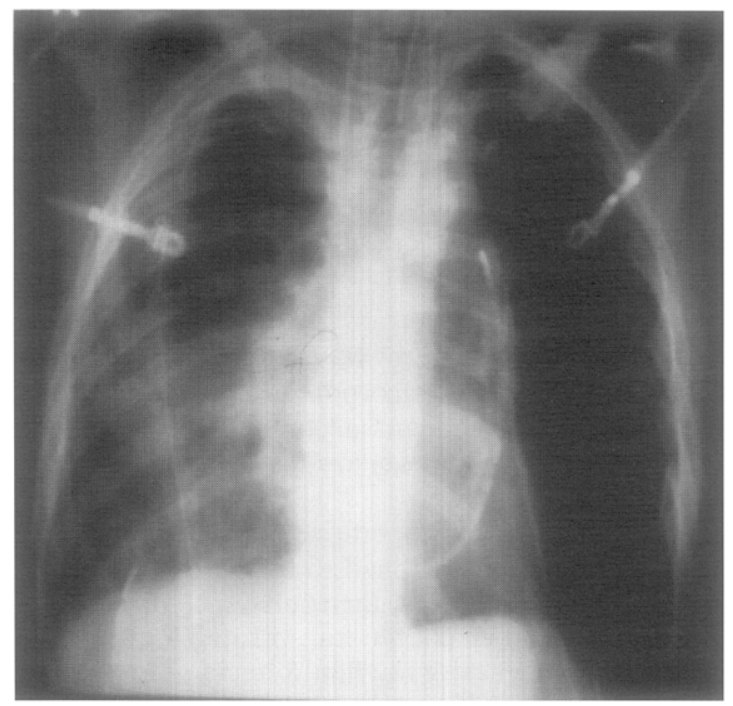

Fig. 2. Chest $\mathrm{x}$-ray film 5 hours after right lung transplantation before surfactant replacement therapy, revealing edema of transplanted lung.

patient was under complete sedation with fentanyl and midazolam infusion.

The compliance reached a plateau at $39 \mathrm{ml} / \mathrm{mm} \mathrm{Hg}$ after 18 hours. PEEP was decreased from 10 to $5 \mathrm{~mm} \mathrm{Hg}$. The increase of tidal volume at 6 hours was caused by decreasing PEEP with maintainance of pressure-controlled ventilation (Fig. 1). After about 6 hours, $\mathrm{FiO}_{2}$ was lowered from $60 \%$ to $35 \%$ with maintainance of an arterial oxygen tension of 100 to $120 \mathrm{~mm} \mathrm{Hg}$. The mean pulmonary artery pressure dropped by $12 \mathrm{~mm} \mathrm{Hg}$ and the mean airway pressure was reduced by $5 \mathrm{~mm} \mathrm{Hg}$. The edematous infiltrate of the transplanted lung on chest $\mathrm{x}$-ray film before surfactant therapy was remarkably reduced on control x-ray film after 12 hours of therapy and was completely resolved after 24 hours (Figs. 2 and 3 ).

After 24 hours surfactant replacement was discontinued without any change in compliance and lung function. Because the clinical situation remained stable, sedation was discontinued 6 hours later. The patient was extubated after 48 hours without signs of pulmonary insufficiency. The clinical course continued to be uneventful, and the patient was dismissed home from the hospital on postoperative day 17.

Reperfusion injury after lung transplantation can usually be treated effectively with PEEP ventilation. In severe cases, however, pulmonary insufficiency necessitates the use of extracorporeal membrane oxygenation. The underlying pathomechanisms are not well known, but laboratory investigations support the theory of impaired surfactant synthesis of a lung caused by ischemic damage to type II pneumocytes before transplantation. ${ }^{1,2}$ Because of these observations and the successful use of surfactant replacement therapy in neonatal respiratory distress syndrome, Novick and associates ${ }^{3}$ speculated in 1991 about surfac-

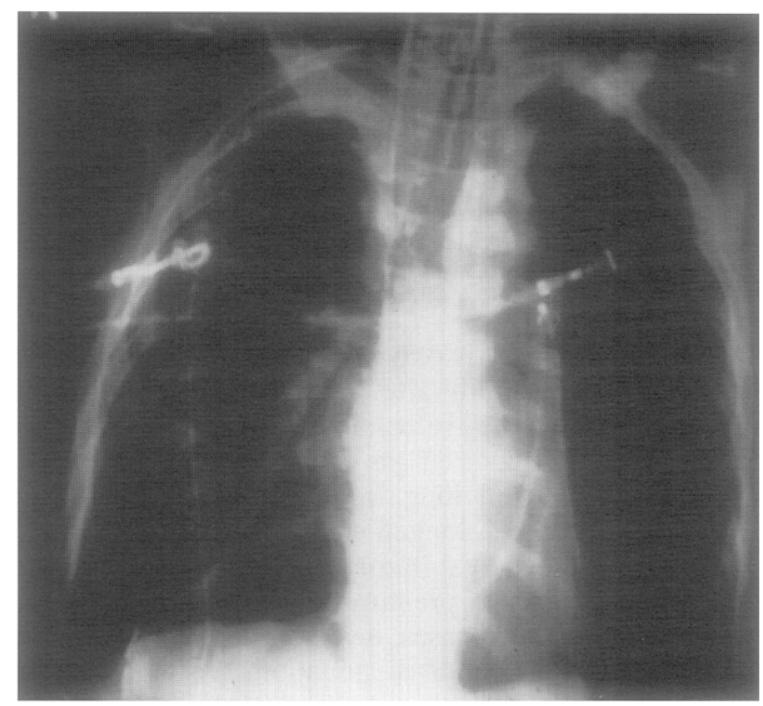

Fig. 3. Chest $x$-ray film 18 hours after right lung transplantation after 12 hours of surfactant replacement therapy.

tant replacement as a "future tool of the lung transplant surgeon." In this case the remarkable increase in compliance from 16 to $30 \mathrm{ml} / \mathrm{mm} \mathrm{Hg}$ after 30 minutes of surfactant therapy reversed a potentially life-threatening situation. This and the rapid improvement of gas exchange and reversal of an interstitial infiltrate have been shown to be typical responses to surfactant replacement therapy in neonatal respiratory distress syndrome. Therefore, this case indicates strong evidence for the effectiveness of surfactant therapy.

Nebulization proved to be a convenient method of application with use of a standard commercially available nebulizer. The software for the ventilator was altered to allow for continuous nebulization. A synthetic surfactant preparation was used because of the high stability of the compound when dispersed.

This case encourages more laboratory and clinical investigations concerning a transient loss of surfactant synthesis after ischemia and the potential role of surfactant replacement therapy as a future tool of treatment in lung reperfusion injury.

\section{REFERENCES}

1. Klepetko W, Lohniger A, Wisser W, et al. Pulmonary surfactant in bronchoalveolar lavage after canine lung transplantation: effect of L-carnitine application. J Thorac Cardiovasc Surg 1990;99:1048-58.

2. Hachida M, Hoorn DSB, Morton DL. A comparison of solutions for lung preservation using pulmonary alveolar type II cell viability. Ann Thorac Surg 1988;45:643-6.

3. Novick RJ, Possmeyer F, Veldhuizen RAW, Menkis AH, McKenzie FN. Surfactant analysis and replacement therapy: a future tool of the lung transplant surgeon? Ann Thorac Surg 1991;52:1194-200. 